\title{
Interactive comment on "Impact of light-absorbing particles on snow albedo darkening and associated radiative forcing over High Mountain Asia: High resolution WRF-Chem modeling and new satellite observations" by Chandan Sarangi et al.
}

\section{Anonymous Referee \#3}

Received and published: 21 March 2019

This study performed WRF-chem high-resolution $(\sim 12 \mathrm{~km})$ model simulations coupled with the SNICAR model to resolve BC/dust-snow interactions and associated albedo reductions. The model results are evaluated with a suite of observations for snow properties and aerosol conditions. The authors further illustrated the effect of model resolution by comparing with a quasi-global WRF-Chem simulation. This study highlights the importance of model resolution and aerosol-snow interactions in modeling the Tibetan Plateau hydroclimate. The manuscript is generally well-organized and well-written. I

Printer-friendly version

Discussion paper 
have a few comments and suggestions to help improve the manuscript.

1. When evaluating modelled LAP concentration in snow, did the authors average the LAP concentrations throughout all the snow layers (up to 5) in the model? Or did the authors only look at specific snow thickness (e.g., top $10 \mathrm{~cm}$ ) in the model? The observed LAP in surface snow may have different sampling thicknesses/depths. More clarifications could be useful. Similar clarifications should also be provided for snow grain size calculations and evaluation.

2. Introduction (Lines 112-114): For the authors' information, there are a number of valuable recent global modeling studies on the LAP-induced snow albedo effect over the Tibetan Plateau which could be included here as references (e.g., Kopacz et al. 2011 ACP, https://doi.org/10.5194/acp-11-2837-2011; He et al. 2014 GRL, https://doi.org/10.1002/2014GL062191; Zhang et al. 2015 ACP, https://doi.org/10.5194/acp-15-6205-2015).

3. Line 343: It is a little weird to identify April-June as the summer season. How about using "pre-monsoon" season?

4. Is there any specific reason to select 2013-2014 water year as the simulation period? Is it because the availability of observations?

5. Another important uncertainty factor the authors did not mention is the snow grain shape effect. Recent studies have shown significant effects from nonspherical snow grain shapes on snow albedo and BC/dust-induced albedo reduction (e.g., Liou et al. 2014 JGR, https://doi.org/10.1002/2014JD021665; Dang et al. 2016 JAS, https://doi.org/10.1175/JAS-D-15-0276.1; He et al. $2017 \mathrm{JC}$, https://doi.org/10.1175/JCLI-D-17-0300.1). I suggest including some discussions on this aspect. Also, did the authors assume spherical snow grains in their model simulations? This should be clarified in the model description.

6. It would be useful if the authors could add a section to discuss the uncertainties 
involved in this study for the estimates of aerosol-induced snow albedo effects. For example, uncertainties from overestimated fSCA and SGS, underestimated NSD, AOD ACPD biases, etc.

Interactive comment on Atmos. Chem. Phys. Discuss., https://doi.org/10.5194/acp-2018-979, 2018. 